\title{
PERCEPÇÕES DE UNIDOCENTES SOBRE A EDUCAÇÃO FÍSICA NOS ANOS INICIAIS DO ENSINO FUNDAMENTAL
}

\author{
Thiago Francisco Rodrigues ${ }^{1}$ \\ Carlos Eduardo Izaguirre da Silva² \\ Jaqueline Copetti ${ }^{3}$
}

\begin{abstract}
RESUMO
O espaço ocupado pela Educação Física no ambiente escolar vem sendo ampliado ao longo do tempo, sobretudo em virtude de importantes reflexões sobre seu verdadeiro papel educacional. Os Anos Iniciais do Ensino Fundamental (Aief) têm-se apresentado como um local de importantes discussões a respeito da atuação dos professores unidocentes ou da possibilidade de atuação de professores especialistas. Desta forma, este estudo tem por objetivo identificar e refletir sobre as percepções de professores unidocentes sobre a Educação Física nos Anos Iniciais. Para tanto foi realizada uma pesquisa qualitativa e exploratória com 15 professoras unidocentes que receberam em suas turmas de trabalho estagiários de um curso de Educação Física. Foram realizadas entrevistas semiestruturadas e os dados avaliados por meio de análise de conteúdo. Os achados apontam um panorama persistente, no qual a Educação Física vem sendo trabalhada de forma limitada, mediante atividades recreativas e brincadeiras, em decorrência de uma formação ineficiente e inespecífica, na qual esta área do conhecimento pode estar sendo colocada em segundo plano. Em contraponto, os avanços da ciência podem estar servindo para desconstruir antigos paradigmas, abrindo espaço para que a Educação Física possa também ser reconhecida por sua influência positiva nos processos relacionados à cognição e à aprendizagem dos alunos.
\end{abstract}

Palavras-chave: Ensino Fundamental. Pesquisa qualitativa. Atividades recreativas. Currículo.

\section{UNIDOCENTES PERCEPTIONS ON PHYSICAL EDUCATION IN THE INITIAL YEARS OF FUNDAMENTAL EDUCATION}

\section{ABSTRACT}

The space occupied by Physical Education in the school environment has been expanded over time, mainly due to important reflections about its true role in this scenario. The Initial Years of Elementary School have been presented as a place of important discussions about the unidocente teachers or the possibility of teachers' performance. Thus, this study aims identify and reflect on the perceptions of the primary teachers about the Physical Education in the Early Years. For that, a qualitative and exploratory research was carried out with fifteen female primary teachers who received trainees from a Physical Education course in their work groups. Semi-structured interviews were conducted and the data evaluated through content analysis. The findings point to a persistent panorama, in which Physical Education has been worked in a limited way, through recreational activities and games, which is due to an inefficient and nonspecific training, in which this area of knowledge may be placed in second plan. In contrast, advances in science may be serving to deconstruct old paradigms, opening space for Physical Education can also be recognized for its positive influence on processes related to students' cognition and learning. Keywords: Elementary school. Early years. Qualitative research. Recreational activities. Curriculum.

RECEBIDO EM: 3/6/2017

ACEITO EM: 3/1/2018

\footnotetext{
${ }^{1}$ Professor de Educação Física, Fisioterapeuta e Especialista em Neurociências Aplicada à Educação. Unipampa. bilachy@yahoo.com.br

2 Professor de Educação Física, Fisioterapeuta e Especialista em Neurociências Aplicada à Educação. Unipampa. eduizaguirre@yahoo.com.br

${ }^{3}$ Professora do Curso de Educação Física da Universidade Federal do Pampa. Doutora em Educação em Ciências. Unipampa. jaquecopetti@yahoo.com.br
} 
Ao longo das últimas duas décadas a relação da Educação Física com a escola vem sendo constantemente estudada, discutida e normatizada, em um movimento que busca desvelar sua verdadeira intencionalidade no contexto educacional. A Base Nacional Comum Curricular, documento recentemente publicado pelo Ministério da Educação, ilustra isso, pois, de forma diferente das normativas que o precederam, apresenta clara e sistematicamente os temas a serem abordados em cada nível de ensino (BRASIL, 2017). Em uma perspectiva que visa a superar antigas fragilidades, orienta (estabelece) uma padronização nacional de objetivos e conteúdos a serem tratados no decorrer da educação básica (RODRIGUES, 2016).

Nas primeiras etapas educacionais, estando os Anos Iniciais do Ensino Fundamental (Aief) inseridos nesse contexto, a Educação Física configura-se como um espaço no qual a criança, de forma orientada, deve explorar a cultura corporal e o movimento, buscando a alfabetização nesta área da linguagem. Nesta fase, apesar da obrigatoriedade como área do saber, a legislação educacional brasileira permite que as aulas de Educação Física sejam conduzidas pelo professor de referência da sala ou unidocente (BRASIL, 2001, 2010). Desta forma (em decorrência disso), o professor de Educação Física acaba por ocupar pouco ou nenhum espaço, ficando à mercê do processo educacional neste importante período educacional, isso em grande parte das escolas públicas do Estado do Rio Grande do Sul (CONTREIRA; KRUG, 2010). Este panorama ganha força no Estado em virtude da Lei Estadual no 10.576/95 (RIO GRANDE DO SUL, 1995) que prevê gratificações nos vencimentos dos professores que atuam em classes unidocentes, o que acaba por incentivar este tipo de atuação. Sobre isso, Fonseca (2006) observa que prevalece entre os professores a ideia de que a gratificação da unidocência pode ser ameaçada em virtude de uma atuação conjunta com professores especialistas, informação que não encontra respaldo na legislação, uma vez que tal gratificação refere-se à estruturação do currículo e não à prática pedagógica unidocente (FONSECA; CARDOSO, 2014).

$\mathrm{Na}$ construção social dos ofícios, reconhecidamente o profissional que deve tratar dos saberes do corpo, da práxis corporal e, mais conceitualmente falando, da cultura corporal do movimento, é o professor de Educação Física. Essa perspectiva transcende o ideário popular, sendo também reconhecida pelos próprios professores unidocentes. Além disso, estes profissionais relatam inúmeras dificuldades e um sentimento de despreparo para o desenvolvimento dos saberes da Educação Física, tema que vem sendo estudado e discutido há algum tempo por pesquisadores da área (ETCHEPARE; PEREIRA; ZINN, 2003; SILVA FILHO; PEREIRA, 2012).

Da forma como se apresenta, a Educação Física nos Aief encontra uma forte tendência em reduzir as aulas apenas a práticas recreativas, jogos desportivos ou em brincadeiras livres, possivelmente deixando de contemplar as demais possibilidades desta importante área do conhecimento (DARIDO, 2011). Os reflexos negativos deste quadro são observados logo em seguida pelos professores de Educação Física, já nos anos finais do Ensino Fundamental, com a presença de muitos alunos com um repertório motor pobre e muito abaixo do esperado para a idade (FONSECA; CARDOSO, 2014). 
No sentido de dar significância ao previamente exposto, Gaya (2009) observa que a Educação Física se distingue das demais disciplinas escolares no que se refere à sua tarefa educativa primordial, pelo fato de educar, formar, socializar e possibilitar experiências por meio das distintas manifestações da corporalidade e do trato único e específico com o corpo. Sendo assim, é possível que esta perspectiva dificilmente seja entendida, reproduzida e ensinada por profissional que não é da área, emergindo daí, talvez, a dificuldade dos professores unidocentes em desenvolver os saberes da Educação Física durante suas aulas, o que, provavelmente, contribui para o estabelecimento do quadro que hoje se apresenta. Nesse sentido, percebe-se uma fragilidade na formação inicial dos professores que atuam em classes unidocentes no contexto estudado, no que se refere à Educação Física. Os conhecimentos adquiridos por estes profissionais em sua formação para atuar com o componente curricular Educação Física são obtidos por meio de apenas uma disciplina específica, tanto na formação de nível médio ou normalista (SCHUTZ, 2011), como na formação em nível superior de Licenciatura em Pedagogia (SILVA; KRUG, 2008), o que parece ser pouco eficiente para o desempenho de um trabaIho mais seguro e qualificado.

A escola como meio educacional tem por dever oportunizar boas possibilidades de práticas corporais para as crianças, pois elas são determinantes para seu desenvolvimento integral. É nesse ambiente que muitas crianças vivenciam pela primeira vez situações de grupo e de movimento dirigido, elementos que sabidamente influenciam no processo de desenvolvimento, aquisição de hábitos e socialização (GALLAHUE; OZMUN; GOODWAY, 2013). Dessa forma, reflexões sobre essa temática mostram-se ainda necessárias.

Com base no exposto, entendemos que a relação da Educação Física Escolar com a unidocência apresenta inúmeras questões que ainda necessitam de investigação e reflexão, induzindo, desta forma, à delimitação do seguinte objetivo de pesquisa: Identificar quais são as percepções de professores unidocentes sobre a Educação Física Escolar nos Aief, após terem recebido em suas turmas de trabalho estagiários de um curso de Licenciatura em Educação Física.

\section{MATERIAIS E MÉTODOS}

Trata-se de um estudo qualitativo de natureza exploratória (POUPART et al., 2012), realizado com professoras unidocentes de duas escolas públicas de Ensino Fundamental do município de Uruguaiana/RS. Propõe-se a descrever como está estruturada a Educação Física escolar nos Aief do município, bem como explorar e contextualizar sobre as percepções de professoras unidocentes em relação à Educação Física nessa etapa de ensino.

Foram envolvidas no presente estudo duas escolas do perímetro urbano do município, estando estas localizadas em bairros distintos da periferia da cidade. Estas escolas foram selecionadas por conveniência, por terem sido campo de Estágio Curricular Supervisionado (ECS) para o curso de Licenciatura em Educação Física de uma das universidades do município, no segundo semestre letivo de 2016. Dessa forma, foram incluí- 
das na presente pesquisa 15 professoras unidocentes do 4 으 e 50 anos destas escolas, as quais receberam em suas turmas de trabalho, durante o ECS, acadêmicos em fase final de formação do referido curso.

As professoras, após receberem os devidos esclarecimentos, consentiram em participar da pesquisa, assinando o respectivo Termo. A coleta dos dados ocorreu por meio de entrevistas semiestruturadas (TRIVIÑOS, 2010), com as questões utilizadas nestas entrevistas tendo sido elaboradas pelos autores, buscando uma aproximação com os objetivos do estudo mediante os seguintes questionamentos:

1. O que é Educação Física para você?

2. Qual é o papel da Educação Física Escolar para você?

3. Qual é a sua opinião sobre a presença da disciplina de Educação Física Escolar nos Anos Iniciais do Ensino Fundamental?

4. Considerando sua formação, você sente-se preparado(a) para ministrar aulas de Educação Física Escolar nos Anos Iniciais do Ensino Fundamental?

5. Qual é a sua opinião sobre a inclusão de um(a) professor(a) de Educação Física nos Anos Iniciais do Ensino Fundamental?

6. Qual é a sua percepção sobre as aulas de Educação Física Escolar conduzidas pelos acadêmicos/estagiários do curso de Educação Física?

As respostas foram obtidas de forma oral, sendo individualmente gravadas por dispositivo digital de captação de áudio, tendo em média oito minutos de duração cada entrevista.

$\mathrm{Na}$ busca por compreender a estruturação da rede municipal de ensino no que se refere aos Aief e, neste cenário, como está sendo tratada a Educação Física Escolar, foram levantadas informações junto a Secretaria Municipal de Educação. Desta forma, foram analisados os documentos e as normativas municipais para a Educação Física nos Aief, bem como foi realizada uma entrevista não estruturada (TRIVIÑOS, 2010) com a coordenadora dos Anos Iniciais.

Para análise dos dados as gravações foram organizadas, transcritas e, posteriormente, foi realizada a análise de conteúdo (BARDIN, 2011). O conteúdo foi classificado em categorias, no sentido de auxiliar a compreensão de cada fala (MINAYO, 2012), tendo como base as respostas e não as perguntas. De forma complementar, foram anexados segmentos de texto que pudessem ser representativos a cada categoria de discussão.

Para preservar o anonimato os sujeitos do estudo foram identificados numericamente como Professor 1, Professor 2 e assim por diante. Esta pesquisa foi aprovada pelo Comitê de Ética em Pesquisa local, sob o Parecer $n^{\circ}$ 1.840.192.

\section{RESULTADOS E DISCUSSÃO}

Este tópico apresenta uma sucinta contextualização do lócus do estudo, com a apresentação de alguns dados em valores numéricos absolutos e/ou relativos. 
O município de Uruguaiana, fronteira Oeste do Estado do Rio Grande do Sul, possui aproximadamente 130.000 habitantes (INSTITUTO..., 2016). A rede municipal de educação conta com 16 escolas de Ensino Fundamental, nas quais foram matriculadas, somente nos Anos Iniciais, aproximadamente 4 mil crianças no ano de 2016 (SECRETARIA..., 2016). Em uma distribuição territorial, 10 destas escolas estão localizadas no perímetro urbano e 6 estão no interior do município para atender à população rural (Tabela 1).

Tabela 1 - Distribuição territorial das escolas municipais e atuação dos professores de Educação Física

\begin{tabular}{lcr}
\hline Localização & No de escolas & Professor de Ed \\
\hline Perímetro urbano & 10 & 0 \\
\hline Interior do município (rural) & 6 & 4 \\
Total & $\mathbf{1 6}$ & $\mathbf{4}$
\end{tabular}

Fonte: SECRETARIA..., 2016.

De acordo com as informações da Secretaria Municipal de Educação, em nenhuma das 10 escolas do perímetro urbano do município há professor de Educação Física atuando de forma isolada ou em conjunto/assessoria nas turmas unidocentes dos Aief, bem como na Educação Infantil. Dessa forma, no que se refere à Educação Física, estas escolas seguem a rotina da maioria das escolas públicas do Estado, com este componente curricular sendo ministrado pelos professores unidocentes nas duas primeiras etapas da Educação Básica. Em virtude disso, podemos afirmar que, ao menos nas escolas do perímetro urbano da rede de ensino do município de Uruguaiana/RS, os professores de Educação Física ganham espaço e podem assumir a responsabilidade pelas práticas corporais no ambiente escolar só a partir do 60 ano, já com turmas dos Anos Finais do Ensino Fundamental, o que se caracteriza como uma inserção tardia desta classe profissional. Ressaltamos que esta inserção tardia dos professores de Educação Física no cenário educacional é um panorama comum em todo o país, constituindo a regra, não a exceção.

Para Fraga (2005), o tema central a ser discutido na relação da Educação Física com as primeiras fases da Educação Básica não deve ser centrado no questionamento de quem deve ser responsável pelas aulas - professores unidocentes ou licenciados em Educação Física. Segundo este autor, o conhecimento produzido pela Educação Física precisa ser incorporado ao currículo, devendo ocupar um lugar compatível e de igualdade com os demais componentes curriculares obrigatórios no cotidiano escolar. Este entendimento, sustentado pelo parecer CNE n. 16 (BRASIL, 2001), defende que o valor educativo ancora-se na qualidade da prática desenvolvida e não na titulação do profissional que a realiza. Acertadamente, este posicionamento dialoga com a estruturação não fragmentada do currículo escolar nesta fase, na qual os campos do saber devem ser articulados de forma harmônica e sem demarcação por área. O posicionamento dos próprios professores unidocentes, no entanto, em estudos realizados em diferentes locais do país, revela que os profissionais mais habilitados para conduzir as aulas de 
Educação Física em todas as etapas da Educação Básica são os professores da área (PEREIRA; NISTA-PICCOLO; DOS SANTOS, 2009; SILVA FILHO; PEREIRA, 2012; DALLA NORA; ZAWITZKI, 2014).

Os tópicos a seguir apresentam os resultados da presente investigação derivados das falas das professoras entrevistadas, estando subdivididos em categorias/eixos norteadores para facilitar a discussão.

\section{A Educação Física Escolar como Sinônimo de Recreação e Brincadeiras}

A Educação Física tem nas práticas corporais a matriz central para o desenvolvimento de seu trabalho pedagógico. Sua abordagem no ambiente escolar ocorre por intermédio de múltiplas possibilidades de inter-relação "corpo e movimento", tendo como conteúdos a serem desenvolvidos ao longo das duas primeiras etapas educacionais os jogos e brincadeiras, os esportes, as ginásticas, as lutas, as práticas corporais de aventura e até os exercícios físicos (BRASIL, 2017).

As manifestações esportivas, contudo, em especial as coletivas, historicamente dominam o campo de atuação da Educação Física nas escolas brasileiras, situação que vem sendo amplamente discutida e condenada por diversos autores (FREIRE, 1989; SOARES et al., 1992). Esta condição dificulta a inclusão de outras práticas corporais no ambiente escolar, prejudica a abordagem de outros conteúdos, bem como acaba por restringir os conhecimentos apenas à dimensão procedimental, deixando de lado importantes manifestações da cultura corporal do movimento (DARIDO; SOUZA JÚNIOR, 2013).

Em contraponto a este panorama, os relatos das professoras entrevistadas apontam que as práticas recreativas e as brincadeiras são as atividades pedagógicas mais utilizadas por elas no trato com a Educação Física nos Aief.

[...] a gente tem uma preparação mais pra recreação, brincadeiras [...] não chega ser exatamente Educação Física [...] a gente leva como Educação Física, mas, eu acredito [...] a gente tem mais como uma recreação (Professora 11).

[...] nós trabalhamos a recreação e não aquelas práticas que as gurias (dupla de estágio) fizeram aqui muito bem trabalhado com eles (Professora 10).

As professoras participantes deste estudo atuam em turmas de 40 e 50 anos do Ensino Fundamental, período em que os alunos já possuem autonomia e um bom controle corporal, o que possibilita uma atuação segura para o desenvolvimento de diferentes práticas corporais de cunho pedagógico. As aulas de Educação Física constituem importante espaço para isso, pois, como afirma Gaya (2009), nelas o professor tem a responsabilidade de explorar, ampliar e contextualizar os saberes do corpo de forma orientada e em conexão com as demais disciplinas e conhecimentos abordados na escola.

Constata-se que, ao se afastarem da concepção esportivista, certamente em decorrência de uma formação inicial de caráter generalista, as professoras apontam um direcionamento para outra forte tendência na Educação Física Escolar, a perspectiva recreacionista (DARIDO; SOUZA JUNIOR, 2013). Nela, costumeiramente são os alunos quem decidem o que fazer durante as aulas, escolhendo as brincadeiras ou os jogos que 
mais lhes convêm, bem como a forma de praticá-los. Isso, por certo, restringe o professor à condição de mero observador ou, quando muito, a um controlador do tempo, com pouca ou nenhuma intervenção pedagógica (DARIDO; RANGEL, 2014).

A raiz pedagógica dessa conduta considera que a essência da Educação Física não é aprender a se mover, mas mover-se para aprender a ser educado (AMES, 1992). Dessa forma a disciplina é, muitas vezes, conduzida por intermédio de objetivos abstratos e sob a perspectiva de que os efeitos educacionais apareçam automaticamente. Em termos práticos, a ênfase das aulas gira em torno da diversão, satisfação e percepção de competência, não havendo maiores compromissos com o processo de ensino e aprendizagem (MARQUES; CATUNDA, 2015).

Em estudo realizado também com professores unidocentes da rede básica de ensino, Silva Filho e Pereira (2012) detectaram dificuldades destes docentes na realização das aulas de Educação Física e, em alguns casos, até o não desenvolvimento desta temática. Os autores pontam que grande parte destes professores oferece apenas a recreação como conteúdo da Educação Física em suas turmas de trabalho. Fonseca e Cardoso (2014) constataram o desconhecimento dos professores unidocentes a respeito da proposta da Educação Física para os Aief contida nos Parâmetros Curriculares Nacionais, fato que acabou por induzir a práticas repetitivas e limitadas a recreação e brincadeiras. Constatações semelhantes também foram encontradas na presente investigação, o que pode ser visualizado nos recortes a seguir:.

[...] o professor da sala de aula trabalha brincadeiras [...] trabalha bastante o lúdico (Professora 2).

[...] quando eles (alunos) fazem conosco eles não têm a noção de Educação Física, é uma noção de recreação, brincadeiras (Professora 14).

As atividades recreativas, as brincadeiras e outras práticas que proporcionam diversão são importantes ferramentas pedagógicas e motivacionais à disposição dos professores para o desenvolvimento dos conteúdos da Educação Física (ETCHEPARE; PEREIRA; ZINN, 2003). As brincadeiras, em especial, estão entre as práticas corporais mais antigas da humanidade, ocupando um lugar muito importante nas mais diversas civilizações e culturas (NEIRA, 2014), contribuindo para o aprendizado das crianças por constituírem uma forma prazerosa de aprender.

Desta forma, obviamente que a utilização no ambiente escolar de atividades recreativas e brincadeiras, não apenas nas aulas de Educação Física, deve ser amplamente incentivada em virtude de seu enorme potencial pedagógico. Estas práticas, contudo, devem ser desenvolvidas com muita responsabilidade e tratadas como algo que necessita de sistematização, planejamento e adequação aos objetivos que se pretende atingir. Com um olhar especial para as aulas de Educação Física nos Aief, as atividades recreativas e brincadeiras apresentam-se como importantes ferramentas introdutórias para a abordagem dos demais conteúdos da cultura corporal, no entanto o que se tem visto, geralmente, é a tentativa de lhes atribuir funções pedagógicas, transformando-as em práticas livres, momento para a imposição de padrões desejáveis de comportamento ou como forma de recompensa pelos longos períodos em sala de aula. 
Fato é que conduzir as aulas em uma perspectiva lúdica, com um formato atrativo e descontraído, é diferente de apenas brincar ou ir para a recreação. A diversão, apesar de ser necessária, não pode ser tratada como principal objetivo das aulas Educação Física, sob pena de que sua proposta deixe de ser educacional e resuma-se a um mero momento recreacional (ETCHEPARE; PEREIRA; ZINN, 2003).

Os motivos que sustentam a necessidade da Educação Física nos Aief estão muito além da diversão. Para Gaya (2009), sua presença no ambiente escolar justifica-se, sobretudo, em virtude de seu valor educativo e pela expectativa de que ela é capaz de contribuir para melhorar a vida das pessoas por meio de uma abordagem única e particular a respeito dos saberes que envolvem o corpo. Desta forma, resumir a Educação Física nos Aief a uma ou duas abordagens - escolhidas por critério de conveniência ou a partir da percepção de autossuficiência do professor - sem a possibilidade de reflexão, progressão e variabilidade de conteúdos, caracteriza, certamente, uma forma subempregada de atuação, acabando por desvirtuá-la de sua tarefa educativa primordial.

\section{O Professor Unidocente no que se Refere à Educação Física: relatos de uma formação ineficiente}

A Lei de Diretrizes e Bases da Educação (BRASIL, 1996) e, mais recentemente, o Parecer n. 11/2010, que fixa as Diretrizes Curriculares para o Ensino Fundamental de nove anos (BRASIL, 2010), reforçam que nas turmas do 10 ao 50 ano do Ensino Fundamental a disciplina de Educação Física pode estar a cargo do professor de referência da turma. Sobre isso, Assis e Pontes (2015) propõem que, mesmo com as recentes mudanças ocorridas no Ensino Fundamental, não foram propostas alterações nas diretrizes para o desenvolvimento da Educação Física nesta etapa de ensino.

Ao professor unidocente é atribuída, ao longo das duas primeiras fases da Educação Básica, a imensa responsabilidade de conduzir todos os temas relacionados à alfabetização e, também, à construção de toda a base para formação posterior do indivíduo. Nesse cenário, a Educação Física impõe-se como mais uma área do saber a ser desenvolvida, podendo ser encarada, em alguns casos, como uma barreira a ser superada.

Existem na literatura vários estudos (ETCHEPARE; PEREIRA; ZINN, 2003; SILVA FILHO; PEREIRA, 2012; DALLA NORA; ZAWITZKI, 2014) destacando que os próprios professores unidocentes relatam dificuldades e, muitas vezes, uma sensação de despreparo para desenvolver os conteúdos da Educação Física em suas práticas pedagógicas. Assim, parece que estamos diante de um quadro persistente que abrange aspectos como a formação inicial dos professores, bem como o cenário político, econômico e pedagógico que sustenta a unidocência da forma como está estruturada (FONSECA; CARDOSO, 2014).

Sobre esse aspecto, todas as 15 professoras entrevistadas relataram que não se sentem preparadas para trabalhar com Educação Física na escola, associando esta condição a uma formação inicial deficiente, tanto na Pedagogia quanto no Magistério. Tal constatação expõe uma lacuna na formação destas docentes, levando a crer que a Educação Física pode estar sendo colocada em segundo plano nos cursos de formação em Pedagogia e Magistério. 
[...] no meu curso de Pedagogia nós tivemos apenas um semestre de Educação Física [...] com menor carga horária [...] foi um ensino burocrático [...] eu não considero que tenha um conhecimento técnico (Professora 3).

[...] porque quando eu fiz a faculdade de Pedagogia, eu tive a didática da Educação Física [...] que é algo muito amplo [...] e eu tive num semestre só [...] tive só a teoria [...] não tive nada prático [...] não me sinto preparada [...] (Professora 5).

[...] não me sinto preparada. Porque no curso de Magistério eles faziam Educação Física conosco, mas não aquela Educação Física preparatória, pra ti passar futuramente para os teus alunos [...] eu não me sinto preparada [...] é muito delicado [...] (Professora 9).

As professoras relacionam as dificuldades encontradas para conduzir as aulas de Educação Física a uma formação inicial ineficiente em seus aspectos teóricos e práticos. Os relatos associam esse panorama a fatores como a carga horária reduzida e a um ensino burocrático e que não aprofunda os conteúdos da Educação Física. A combinação destes fatores traz à tona uma sensação de despreparo e insegurança na prática pedagógica destas docentes. Todos perdem: a Educação Física, os professores e, sobretudo, os alunos.

Sobre isso, Gatti (2010) constatou que nos cursos de formação docente os conteúdos das disciplinas a serem ministradas na Educação Básica, entre elas a Educação Física, aparecem apenas esporadicamente nas matrizes curriculares, com abordagens genéricas e/ou superficiais, na grande maioria dos casos, o que implica práticas pedagógicas fragilizadas dos futuros profissionais. A autora relata ainda que ocorre um desequilíbrio da relação teórico-prática dos conteúdos, o que induz a uma formação abstrata e pouco integrada ao real contexto de atuação do professor, a escola.

[...] a minha faculdade é a aprendizagem [...] é mais a alfabetização, em si [...] da Educação Física eu sei quase nada (Professora 5).

[...] não me sinto nem um pouco capaz [...] de aplicar a forma correta [...] de aplicar a prática [...] devido a não termos essa formação [...] (Professora 8).

Fonseca e Cardoso (2014) chamam a atenção para os relatos de reduzida formação para o trabalho com o componente curricular Educação Física durante a formação inicial de professoras unidocentes entrevistadas em uma cidade do interior gaúcho. As autoras sinalizam que, em decorrência desta formação, os professores acabam tendo uma visão limitada sobre a Educação Física, encontrando dificuldades para explorar suas potencialidades como área do saber. A deficiência na formação profissional também foi ressaltada por Silva Filho e Pereira (2012) como um dos obstáculos para o desenvolvimento de um trabalho mais qualificado com a Educação Física nos Aief em uma cidade da região metropolitana do Estado de Mato Grosso.

Ao analisarem o currículo do curso de Pedagogia de uma instituição pública de Ensino Superior do Estado do Rio Grande do Sul, Silva e Krug (2008) encontraram um documento pouco estruturado no que se refere à prática pedagógica da Educação Física. O documento previa a oferta de apenas uma disciplina específica na grade curricular, o que se mostrou insuficiente na preparação dos futuros profissionais para atuação docente. 
Desta forma, entendemos que para o desempenho de uma prática docente satisfatória é necessário que o professor compreenda adequadamente os fatores que envolvem as temáticas que se propõe a ensinar, por meio de uma fundamentação teórica e prática consistente. Quando isso não ocorre, e os relatos das entrevistadas no presente estudo indicam claramente isso, o docente corre o risco de desenvolver práticas educativas ineficientes, oferecendo aos alunos, quando muito, frações inexpressivas do conhecimento.

[...] eu sinto que meu conhecimento é pouco [...] (Professora 13).

[...] nós trabalhamos com eles [...] sem aquele fundamento de quem é especializado [...] fazemos o básico do básico (Professora 15).

É importante refletirmos que a presença da Educação Física no ambiente escolar é assegurada por lei. No entendimento de Gaya (2009), a mesma lei que garante sua presença nas escolas exige que os professores que com ela trabalham tenham claro qual é o seu papel no currículo escolar. Assim como consta no artigo 26, § 3 ㅇ da LDB - A Educação Física, integrada à proposta pedagógica da escola, é componente curricular obrigatório da Educação Infantil e do Ensino Fundamental [...] (BRASIL, 1996, p. 19). E ainda, como reafirma a Base Nacional Comum Curricular:

[...] a Educação Física oferece uma série de possibilidades para enriquecer a experiência das crianças [...] permitindo o acesso a um vasto universo cultural. Esse universo compreende saberes corporais, experiências estéticas, emotivas, lúdicas [...] Cada prática corporal propicia ao sujeito o acesso a uma dimensão de conhecimentos e de experiências aos quais ele não teria de outro modo. A vivência da prática é uma forma de gerar um tipo de conhecimento muito particular e insubstituível e, para que ela seja significativa, é preciso problematizar, desnaturalizar e evidenciar a multiplicidade de sentidos e significados [...] (BRASIL, 2017, p. 171-172).

Áreas do saber como a Educação Física, em virtude da particularidade de seus conteúdos, valores e significados, deveriam ser repensadas na grade curricular dos cursos de formação que habilitam para a atuação unidocente. A própria relação entre a unidocência e a Educação Física necessita de uma reformulação urgente. A proposta tradicional de ensino globalizado e não fragmentado, obviamente, qualifica e dá sentido ao processo de ensino-aprendizagem, porém as deficiências e dificuldades de caráter teórico e prático relatadas pelas professoras unidocentes no presente estudo reforçam um panorama previamente descrito por outras pesquisas e, sobretudo, apontam para a necessidade de mudanças.

Na vanguarda dessas mudanças cabe ressaltar a proposta curricular do Estado de São Paulo, que desde o ano de 2002 orienta que em todas as etapas educacionais as aulas de Educação Física sejam conduzidas por professores licenciados na área, em conjunto com o professor regente das turmas (SÃO PAULO, 2002), o que representa um avanço a respeito desta temática. A proposta paulista justifica esta mudança ao considerar a importância desse componente curricular na formação das crianças, incentivando a prática da Educação Física no ambiente escolar por meio de um trabalho conjunto entre profissionais com diferentes formações. 
Assim, o caminho sinalizado para superar antigas fragilidades - entre elas a imensa dificuldade encontrada pelos professores unidocentes em trabalhar com Educação Física - aponta que a atuação conjunta de professores pedagogos/magistério e professores de Educação Física é uma importante estratégia (FRAGA; 2005; DALLA NORA; ZAWITZKI, 2014), na qual a proposta pedagógica ganha qualidade ao possibilitar que 0 corpo, na condição de objeto de estudo e aprendizado, possa ser explorado, representado e usufruído sob a perspectiva de profissionais com diferentes formações.

\section{A Educação Física e suas Contribuições para Além do Corpo}

A escola tem um papel determinante na formação e na aquisição dos hábitos das crianças, constituindo-se num importante núcleo social. É na escola que as crianças e os adolescentes passam boa parte do dia recebendo dos professores, orientadores e dos próprios colegas diferentes estímulos no sentido de bem desenvolver suas capacidades cognitivas, motoras, afetivas e sociais. Nesse sentido, a Educação Física, como uma disciplina que se desenvolve pelo e por meio do corpo, tem a possibilidade de contribuir em aspectos que vão muito além da reprodução de gestos motores.

A Educação Física caracteriza-se como uma disciplina singular, capaz de atuar diretamente na promoção da saúde mediante a incentivo à prática de um estilo de vida mais ativo e saudável. Contribui, também, de forma significativa no processo de desenvolvimento psicomotor e cognitivo dos alunos, o que traz implicações diretas no rendimento escolar (MARQUES; CATUNDA, 2015). As professoras unidocentes identificam estas possibilidades da Educação Física e relatam isso em suas falas:

[...] a primeira organização do aluno é a organização ampla [...] em relação ao próprio corpo e ao espaço [...] essa organização, uma vez bem fundamentada, bem trabalhada na Educação Física, se espelha nas outras habilidades acadêmicas do aluno [...] seja na organização do caderno, na capacidade de sequenciar e organizar pensamentos [...] é muito importante (Professora 3).

[...] o movimento, em si, ajuda no próprio dia a dia da escola [...] na sala de aula deles [...] ajuda nas outras matérias, nas outras disciplinas e habilidades [...] na saúde deles (Professora 8).

[...] na aula a gente consegue também perceber que eles tiveram um crescimento, eu consegui perceber a diferença mais no cognitivo [...] (Professora 10).

Diversos estudos têm demonstrado uma correlação positiva entre o desenvolvimento motor e o desempenho cognitivo (ROEBERS et al., 2014; VAN DER FELS et al., 2015) levando a crer que o primeiro atua em favor do segundo e vice-versa. Tal proposição põe por terra uma construção secularmente (mal)construída, estereotipada e preconceituosa que supervaloriza os saberes intelectuais em detrimento dos saberes do corpo (GAYA, 2014).

Em uma perspectiva que aos poucos ganha espaço, os aspectos motores, físicos e corporais, tão próprios da Educação Física, aproximam-se do viés primário e dualístico da escola: ensinar-aprender. Dessa forma, este componente curricular que, historica- 
mente, foi tratado como inferior, opcional e submisso, vem ganhando notoriedade e importância nos primeiros anos da educação básica, o que podemos perceber nas falas das professoras:

[...] tem que ter a Educação Física na escola [...] até porque é um meio que ajuda dentro da sala de aula [...] trabalha a questão de atenção [...] até mesmo o emocional da criança [...] se não tem Educação Física, reflete na sala (Professora 11).

[...] é fundamental para o desenvolvimento da criança, principalmente pra escrita [...] (Professora 7).

A participação de crianças em idade escolar da prática de atividades físicas, incluindo as aulas de Educação Física, atua positivamente sobre os processos envolvidos na cognição e na aprendizagem (MOTA et al., 2015), apontando o benefício das práticas corporais sobre processos de memória, atenção, tempo de reação, consequentemente levando a uma melhora no desempenho escolar das crianças (CHADDOCK et al., 2011). Ganhos significativos relacionados à leitura foram constatados por Murray et al. (2007), em decorrência de programas de intervenção com Educação Física Escolar, mesmo com a redução do número de horas destinadas às demais disciplinas em favor deste componente.

Cabe ressaltar que a Educação Física tem seus próprios objetivos, estando relacionados ao desenvolvimento motor, à promoção e ao incentivo à saúde, bem como à interação com as questões socioculturais envolvidas nas diversas práticas corporais (BRASIL, 2017). Parece ser evidente, contudo, que uma maior participação dos alunos em atividades físicas, sobretudo as atividades orientadas, acaba por refletir de forma positiva em indicadores de desempenho cognitivo, desta forma impactando no desempenho escolar.

Ao considerarmos os inúmeros benefícios que a prática de atividades físicas pode trazer para as diversas populações, em especial para as crianças em idade escolar, parece óbvia a constatação de que a inclusão de professores de Educação Física atuando nas primeiras etapas educacionais de nossas escolas é necessária, inclusive considerando os relatos das professoras entrevistadas no presente estudo confirmam essa proposição.

Um recente estudo conduzido na Suécia (BUNKETORP KÄLL et al., 2015) adverte que um programa de incentivo à prática de atividades e exercícios físicos precocemente nas escolas promoveu melhoras importantes no desempenho escolar dos estudantes, bem como mostrou-se eficaz no incentivo à adoção de comportamentos fisicamente ativos. Em um período em que as doenças relacionadas ao sedentarismo crescem em uma escala assustadora, este aspecto também mostra-se relevante.

Desta forma, a Educação Física escolar vem deixando de ser vista apenas como um recurso pedagógico que se limita ao corpo em seus aspectos meramente biológicos. Mais recentemente, em virtude da quebra de antigos paradigmas pela Ciência, a área de Educação Física vem sendo encarada como um importante recurso no processo de aprendizagem e na melhora do desempenho escolar em decorrência de sua, ainda pouco explorada, relação com os aspectos cognitivos (LEES; HOPPIKINS, 2013; MEREGE FILHO et al., 2014; MOTA et al., 2015). Por outro lado, já é consagrada sua relação com outros elementos educacionais, como a regulação de comportamentos em grupo, a construção de relações sociais, a adoção de hábitos saudáveis e a transmissão de valores sociais e culturais (MARQUES; CATUNDA, 2015; SOUZA; MOURA; ANTUNES, 2016). 


\section{CONCLUSÕES}

Com base no contexto estudado, a prática da Educação Física nos Aief, de forma geral parece não encontrar na unidocência os necessários espaço e importância, ainda que seja inegável o reconhecimento da conveniência de sua presença. Isso se dá, muito provavelmente, pelo fato de ser desenvolvida sob a perspectiva de professores com formação em Pedagogia e Magistério, o que, sob hipótese alguma desqualifica a prática, mas sim acaba por restringir seu imenso potencial educativo.

O trabalho com o componente curricular Educação Física reflete um panorama sustentado legal e pedagogicamente em todo país, no qual são ceifadas precocemente as possibilidades de atuação dos professores de Educação Física. Desta forma, esta classe profissional só encontra espaço na escola a partir da terceira fase do Ensino Básico, o que aqui denominamos como inserção tardia. Este quadro parece provocar desconforto não apenas para os professores de Educação Física, mas também para aqueles que lecionam nas turmas unidocentes pelo Brasil afora.

Com relação às atividades mais utilizadas pelos professores unidocentes nos momentos destinados à Educação Física, as práticas recreativas e as brincadeiras apresentaram-se como atividades livres supervisionadas por estes docentes, o que se caracterizou como uma forma limitada de atuação, por não possibilitar a reflexão, a variabilidade, nem a progressão de conteúdos. Este panorama encontra uma relação direta com os relatos de insegurança, conhecimento limitado e despreparo teórico-prático para o trabaIho com os saberes da cultura corporal do movimento, evidenciando assim a necessidade de atuação do profissional licenciado em Educação Física. O caminho assinalado para superar estas fragilidades indica que a atuação conjunta entre professores unidocentes e professores de Educação Física nos Aief apresenta-se como uma importante estratégia para qualificar a proposta pedagógica e, consequentemente, melhorar a qualidade do ensino.

Cabe ainda destacar que os avanços da ciência parecem estar servindo para desconstruir velhos paradigmas, abrindo espaço para que a Educação Física possa ser reconhecida por sua influência positiva nos processos relacionados à cognição, à aprendizagem e, consequentemente, no desempenho escolar dos alunos, podendo assim alcançar novos significados e perspectivas no cenário educacional.

Desta forma, acredita-se que a relevância do presente estudo esteja em retratar e discutir o espaço ocupado pela Educação Física nos Aief que há bastante tempo permeia os periódicos da Educação e Educação Física, incentivando, dessa forma, novas pesquisas relacionadas ao tema de maneira mais aprofundada e abrangente.

\section{REFERÊNCIAS}

AMES, Carole. Achievement goals, motivational climate, and motivational processes. In ROBERTS, G. (Ed.). Motivation in Sport and exercise. Champaing, IL: Human Kinetics, 1992. p. 161-176.

ASSIS, Amanda Dória; PONTES, Maicon Felipe Pereira. Educação Física nos anos iniciais do Ensino Fundamental: repensando a atuação docente. Motrivivência, v. 27, n. 45, p. 113-123, 2015.

BARDIN, Laurence. Análise de conteúdo: edição revisada e ampliada. 1. ed. São Paulo: Edições 70, 2011. BRASIL. Base Nacional Comum Curricular. Terceira Versão, 2017. Disponível em: <http://basenacionalcomum.mec.gov.br/images/BNCC_20dez_site.pdf>. Acesso em: 5 jan. 2018. 
Lei de Diretrizes e Bases da Educação. Lei no 9.394, de 20 de dezembro de 1996. Estabelece as Diretrizes e Bases da Educação Nacional. Brasília, DF, 1996.

Ministério da Educação, Conselho Nacional de Educação, Parecer n. 16, de 3 de julho de 2001. Consulta quanto à obrigatoriedade da Educação Física como componente curricular na Educação Básica e sobre a grade curricular do curso de Educação Física da rede pública de ensino. Disponível em: <http:// portal.mec.gov.br/cne/arquivos/pdf/pceb16_01.pdf>. Acesso em: 5 dez. 2016.

Ministério da Educação, Conselho Nacional de Educação, Parecer n. 11, de 7 de julho de 2010. Diretrizes Curriculares Nacionais para o Ensino Fundamental de 9 (nove) anos. Disponível em: <http:// portal.mec.gov.br/profuncionario/323-secretarias-112877938/orgaos-vinculados-82187207/15074-ceb-2010-sp-1493348564>. Acesso em: 5 dez. 2016.

BUNKETORP KÄLL, Lina et al. Effects of a Curricular Physical Activity Intervention on Children's School Performance, Wellness, and Brain Development. Journal of School Health, v. 85, n. 10, p. 704-713, 2015.

CHADDOCK, Laura et al. Aerobic fitness and executive control of relational memory in preadolescent children. Medicine \& Science in Sports \& Exercise, v. 43, n. 2, p. 344-349, 2011.

CONTREIRA, Clairton Balbueno; KRUG, Hugo Norberto. Educação Física nas séries iniciais do ensino fundamental: um estudo de caso com professores unidocentes. Lecturas: Educación Física y Deportes, Revista Digital, v. 15, n. 150, 2010. Disponível em: <http://www.efdeportes.com/efd150/educacao-fisica-com-professores-unidocentes.htm>. Acesso em: 5 dez. 2016.

DALLA NORA, Daiane; ZAWITZKI, Rosalvo Luis. A educação física nos anos iniciais com professores unidocentes. Cadernos de Formação RBCE, p. 68-79, 2014.

DARIDO, Suraya Cristina (Org.). Educação Física: compartilhando experiências. São Paulo, SP: Ed. Phorte, 2011.

DARIDO, Suraya Cristina; RANGEL, Irene Conceição Andrade. Educação Física na escola: implicações para a prática pedagógica. 2. ed. Rio de Janeiro, RJ: Guanabara Koogan, 2014.

DARIDO, Suraya Cristina; SOUZA JUNIOR, Osmar Moreira. Para ensinar Educação Física: possibilidades de intervenção na escola. 7. ed. Campinas, SP: Papirus, 2013.

ETCHEPARE, Luciane Sanchotene; PEREIRA, Érico Felden; ZINN, João Luiz. Educação Física nas séries iniciais do ensino fundamental. Revista da Educação Física, Maringá, v. 14, n. 1, p. 59-66, 2003.

FONSECA, Denise Grosso da; CARDOSO, Lisiane Torres. Educação Física nos anos iniciais do Ensino Fundamental: a questão da unidocência. Kinesis, v. 32, n. 1, 2014.

FONSECA, L. G. da. Significados das aulas de Educação Física para professores unidocentes. 2006. TCC (Licenciatura em Educação Física) - Esef, UFRGS, Porto Alegre, 2006.

FRAGA, Alex Branco. Educação Física nos primeiros anos do Ensino Fundamental brasileiro. Lecturas: Educación Física y Deportes, Revista Digital, v. 10, n. 90, 2005. Disponível em: <http://www.efdeportes.com/ efd90/ensino.htm>. Acesso em: 5 dez. 2016.

FREIRE, João Batista. Educação de corpo inteiro: teoria e pratica da Educação Física. Campinas: Scipione, 1989.

GALLAHUE, David L.; OZMUN, John C.; GOODWAY, Jackie D. Compreendendo o desenvolvimento motor: bebês, crianças, adolescentes e adultos. 7. ed. Porto Alegre: Editora Artmed, 2013.

GATTI, Bernardete Angelina. Formação de professores no Brasil: características e problemas. Educação \& Sociedade, v. 31, n. 113, p. 1.355-1.379, 2010.

GAYA, Adroaldo. Educação Física: a vertente pedagógica da cultura corporal do movimento humano ou 100 Parágrafos em defesa da formação única: Subsídios para o debate sobre a reformulação curricular na Esef-UFRGS. Porto Alegre: Universidade Federal do Rio Grande do Sul; Escola de Educação Física, 2009.

GAYA, Adroaldo et al. Educação Física: ordem, caos e utopia. Belo Horizonte: Casa da Educação Física, 2014.

INSTITUTO BRASILEIRO DE GEOGRAFIA E ESTATÍSTICA (IBGE). Uruguaiana. 2016. Disponível em: <http:// cidades.ibge.gov.br/xtras/perfil.php?lang=\&codmun=432240\&search=rio-grande-do-sul $\mid$ uruguaiana $>$. Acesso em: 5 dez. 2016.

LEES, C.; HOPKINS, J. Effect of Aerobic Exercise on Cognition, Academic Achievement, and Psychosocial Function in Children: A Systematic Review of Randomized Control Trials. Prev Chronic Dis, v. 10, out. 2013. DOI: http://dx.doi.org/10.5888/pcd10.130010.

MARQUES, Adilson; CATUNDA, Ricardo. Educação Física no currículo escolar: para que serve? Que opções existem? O que queremos escolher? Fiep Bulletin, v. 85, Special Edition, 2015. Disponível em: <http:// www.fiepbulletin.net/index.php/fiepbulletin/article/view/85.a2.132>. Acesso em: 5 dez. 2016. 
MEREGE FILHO, Carlos Alberto Abujabra et al. Influência do exercício físico na cognição: uma atualização sobre mecanismos fisiológicos. Revista Brasileira de Medicina do Esporte, São Paulo, v. 20, n. 3, p. 237241, jun. 2014.

MINAYO, Maria Cecília de Souza. Pesquisa social: teoria, método e criatividade. 31. ed. Petrópolis, RJ: Vozes, 2012.

MOTA, João et al. Atividade física e rendimento acadêmico - uma revisão sistemática de sete revisões sistemáticas. Journal of Sport Pedagogy and Research, v. 1, n. 6, p. 24-29, 2015.

MURRAY, Nancy G. et al. Coordinated school health programs and academic achievement: A systematic review of the literature. Journal of School Health, v. 77, n. 9, p. 589-600, 2007.

NEIRA, Marcos Garcia. Práticas corporais: brincadeiras, danças, lutas, esportes e ginásticas. São Paulo: Ed. Melhoramentos, 2014.

PEREIRA, Raquel Stoilov; NISTA-PICCOLO, Vilma Leni; DOS SANTOS, Sheila Aparecida Pereira. A Educação Física nas séries da fase inicial do ensino fundamental: olhar do professor polivalente. Revista da Educação Física/UEM, v. 20, n. 3, p. 343-352, 2009.

POUPART, Jean et al. A pesquisa qualitativa: enfoques epistemológicos e metodológicos. 3. ed. Petrópolis, RJ: Vozes, 2012.

RIO GRANDE DO SUL. Lei no 10.576, de 14 de novembro de 1995. Dispõe sobre a Gestão Democrática do Ensino Público e dá outras providências. Porto Alegre, RS, 14 nov. 1995. Disponível em: <http://www. educacao.rs.gov.br/dados/lei_10.576_compilado.pdf>. Acesso em: 5 dez. 2016.

RODRIGUES, Anegleyce Teodoro. Base Nacional Comum Curricular para a área de linguagens e o componente curricular Educação Física. Motrivivência, v. 28, n. 48, p. 32-41, 2016.

ROEBERS, Claudia et al. The relation between cognitive and motor performance and their relevance for children's transition to school: a latent variable approach. Human Movement Science, v. 33, p. 284-297, 2014.

SÃO PAULO (Estado). Resolução n. 184, de 27 de dezembro de 2002. Dispõe sobre a natureza das atividades de Educação Artística e de Educação Física nas séries do ciclo I do Ensino Fundamental das escolas públicas estaduais. Disponível em: <http://www.educacao.sp.gov.br/lise/sislegis/detresol.asp?strAto $=200212270184>$. Acesso em: 5 dez. 2016.

SCHUTZ, Mariane Bierhals. A formação de normalistas para o trato da educação física nas séries iniciais do Ensino Fundamental. 2011. TCC (Licenciatura em Educação Física) - Esef, UFRGS, Porto Alegre, 2011.

SECRETARIA MUNICIPAL DE EDUCAÇÃO (Uruguaiana/RS). Entrevista não estruturada sobre a Educação Física no município de Uruguaiana/RS. Thiago Francisco Rodrigues, nov. 2016. Gravação de som.

SILVA FILHO, Manoel Francelino da; PEREIRA, Raquel Stoilov. Educação Física e professores polivalentes: o caso das escolas públicas municipais de Várzea Grande. Revista Mackenzie de Educação Física e Esporte, v. 11, n. 2, 2012.

SILVA, Marcio Salles da; KRUG, Hugo Norberto. A formação inicial de professores de Educação Física e de Pedagogia: um olhar sobre a preparação para a atuação nos anos iniciais do ensino fundamental. Lecturas: Educación Física y Deportes, Revista Digital, v. 13, n. 123, p. 1-14, ago. 2008. Disponível em: <http:// www.efdeportes.com/efd123/a-formacao-inicial-de-professores-de-educacao-fisica-e-de-pedagogia. htm>. Acesso em: 5 dez. 2016.

SOARES, Carmen Lúcia et al. Metodologia do ensino de Educação Física. São Paulo: Cortez Editora, 1992. SOUZA, Cleyton Batista; MOURA, Diego Luz; ANTUNES, Marcelo Moreira. A percepção de professores polivalentes do Ensino Fundamental sobre a Educação Física. Revista Brasileira de Ciências do Esporte, v. 38, n. 4, p. 376-383, 2016.

TRIVIÑOS, Augusto Nibaldo Silva. Introdução à pesquisa em ciências sociais: a pesquisa qualitativa em educação. 1. ed. São Paulo: Atlas, 2010.

VAN DER FELS, Irene et al. The relationship between motor skills and cognitive skills in 4-16 year old typically developing children: A systematic review. Journal of Science and Medicine in Sport, v. 18, n. 6, p. 697-703, 2015. 